\title{
Economic impact of autonomous vehicles in Spain
}

\author{
Efrén Alonso ${ }^{*^{*}}$ (D), Cristina Arpón ${ }^{1}$, María González ${ }^{1}$, Ramón Ángel Fernández ${ }^{2}$ and Mariano Nieto ${ }^{3}$
}

\begin{abstract}
Background: Pollution, traffic accidents, and congestion are huge problems in most urban areas. Autonomous and electric vehicles are leading our society to a new mobility model, also known as the New Era of Transportation (NERTRA). Mobility is a strategic issue for any country, and this change of model will mean, in addition to a great technological revolution, an economic revolution.

Methodology: The purpose of this work is to carry out a study of the main economic sectors affected in Spain and evaluate the economic impact that autonomous vehicles will have on each one. Data from this sector have been collected, analyzing the economic and technological factors that will affect to a greater or lesser extent and made evolution forecasts.

Results: The study presents three different scenarios depending on how the transition progresses. The results are presented by each sector in each of these scenarios. These results have great value for the industry itself and the professionals affected, as well as for the authorities of the country to take the appropriate measures from the beginning of the transition. The sectors directly affected by this change represent more than $38 \%$ of the gross domestic product of Spain. Key factors, such as technological innovation in vehicles, and the emergence of new business and mobility models determine drastic changes in some important sectors. It is important to make quick decisions both from administrations and from the industry itself to adapt to new mobility.
\end{abstract}

Keywords: Autonomous vehicles, Mobility, Economy, Spain, NERTRA, GDP

\section{Introduction}

Autonomous vehicles are a disruptive change in transport systems. These vehicles will change the way people and goods move, and also the way we do business. Research on autonomous vehicles has grown significantly in the last decade. In 2003, the Grand Challenge was launched by the Defense Advanced Research Projects Agency (DARPA) to spur innovation in unmanned ground vehicle navigation. In 2005, Stanford's robot "Stanley" was finished the race ahead of all other vehicles and won the challenge [1]. Companies like Tesla, Uber, Lyft, or Google, among many others, have developed autonomous technologies in order to have autonomousdriving commercial services. In June 2018 Waymo's

\footnotetext{
* Correspondence: ealonf00@estudiantes.unileon.es

'Drotium, a Mobility Company, Avenida de los Jesuitas 13, 24007 León, Spain Full list of author information is available at the end of the article
}

autonomous vehicles fleet had self-driven more than 7 million miles, mostly on city streets [2].

A great revolution is coming in transport, and the key issue that determines the success of these technologies is the huge problems they will solve: pollution, accidents, and congestion. Air pollution is a very important environmental and social issue. Particulate matters, ozone, nitrogen dioxide, benzene, among other pollutants, have adverse effects on human health and the environment. The 2016 European air quality report, published by EEA, showed that 31,520 people died in Spain that year because of pollution [3]. It estimates that over 520,000 people die each year in Europe because of pollution. Traffic accidents are a social drama. In 2016, 102,635 accidents were registered in Spain and 1810 people died [4]. These fatalities have major economic impacts; the cost is on the order of 10,3 billion $€$ per year in Spain. 
This issue is really a large-scale problem, the World Health Organization estimated that 1,25 million people died in the world in 2013 due to traffic accidents [5]. The study of the NHTSA estimates that about 93\% of accidents are caused by human factors [6]. Congestion and bottlenecks are a great concern of many cities all around the world, the bigger the metropolitan area, the greater the importance of this issue. A recent study of the impact of traffic congestion in different cities of Spain estimates that Spanish people spent an average of $17 \mathrm{~h}$ in congestion in 2017 [7]. The worst cities are Madrid and Barcelona, where this value increases to 42 and $33 \mathrm{~h}$, respectively. It means that Spanish people spend over 830 million hours per year in congestion.

Electric vehicles have the potential to eliminate almost all the emissions from the combustion engine vehicles while the power generation will be sustainable [8]. Autonomous vehicles have the potential to dramatically reduce crashes [9]. Artificial intelligence and communication technologies bring new solutions and business models, such as ride-sharing services, on-demand services, or "Mobility as a service" (MaaS), which will reduce congestion in urban areas.

The economic effects of this revolution in transport will be very remarkable. One of the first analyses estimated the economic impact of autonomous vehicles up to $\$ 1.9$ trillion per year by 2025 [10]. Recent research finds that autonomous driving technology will enable a new economy worth $\$ 7$ trillion in 2050 [11].

Technological innovation advances much faster than the legislation that allows its deployment. However, legislation is important to drive the transition to new mobility models. In recent years, Spanish policymakers have already begun this task. In 2015, the Directorate General for Traffic of Spain approved a procedure to regulate and authorized research tests of autonomous vehicles in public roads, through Instruction $15 / \mathrm{V}-113$ [12]. In 2017, the Congress of Deputies of Spain unanimously approved the NLP "Non-Law Proposition for the promotion and development of the autonomous vehicles (Ref. $162 / 000451)$ " in order to develop national legislation for these technologies.

This national legislation contemplates any type of test that manufacturers, companies, universities, or research centers wish to carry out. Each autonomous vehicle must obtain a certificate from a technical service accredited by ENAC (National Accreditation Entity) to carry out these experimental tests. This certificate, depending on the characteristics and technology of the vehicle, will limit its scope of operation. Furthermore, each vehicle must have one or more drivers with a valid driver's license. The driver may be inside the vehicle or act remotely and must be able to take full control of the vehicle in the event of any eventuality that arises.
At the regional level, the first administration to legislate this sector was Castilla y León Government through Law 9/2018, of December 20, on public transport for passengers by roads by regulating autonomous driving and the new mobility system [13]. On March 18, 2019, the City Council of León signed the agreement that allows experimental tests of autonomous vehicles in the streets of this city. León became in the first Spanish city with a regulation to become a NERTRA City.

Based on the NPL of the Congress of Deputies, it is expected that in the coming months and years, new regulations will be developed in many other regions throughout the country. A good example is the pilot projects carried out recently in cities such as Madrid, Málaga, or Vigo. From a legislative point of view, we can consider that Spain has taken the first steps in the transition towards a new mobility model.

This paper seeks to analyze the impact of autonomous vehicles in the Spanish economy and the main business sectors affected. Section 2 presents the methodology used in this study. Section 3, part 1 shows the results obtained using this methodology, and part 2 shows the analysis of each of the sectors studied in this paper. Finally, the conclusions are presented.

\section{Methods}

The main objective of this study is to determine how transport will evolve in Spain with the introduction of new technologies, which will lead to a mobile park based on autonomous and electric vehicles.

For this, a collection of data regarding different transport subsectors has been carried out. Macroeconomic figures are analyzed to establish a current map of the state of the sector. Specifically, the Gross Domestic Product will be used as the main indicator of the study because it shows the market value of different sectors in specific periods of time. The study is based on available data whose sources are different organizations and entities referenced throughout the manuscript. Forecasts are made for the future situation of the irruption of these new technologies in transport.

Throughout this article, a series of data regarding the industries considered as most affected by the new mobility paradigm are presented. Secondary sources have been used for data collection, which provides key indicators in the analysis of the current situation of these industries concerning transport. Asserting that a transition phase is going to take place, where autonomous vehicles are going to live together with engine vehicles, an estimation of the future situation of each industry has been made. Different forecasts made on the entry of autonomous vehicles into the market agree that it will not be linear, and will resemble an exponential curve [9, 14]. This means that in the early stages autonomous vehicles will 
have a small market share, while in the last stage they will experience great growth. According to these forecasts, the authors have selected three stages of the transition to carry out the study, the first with a market share of $20 \%$, the second with $50 \%$, and the third with $100 \%$, considering them as the most representatives.

Through the analysis of time series, some key indicators are analyzed that demonstrate how the sector would evolve if the transport model continued as before if changes and new technologies were not introduced.

On the other hand, an estimate is made of the variation of the indicators in the proposed scenarios.

For the preparation of the time series, the ARIMA model (an acronym for autoregressive integrated moving average) has been applied and is represented as follows:

$$
Y_{t}=-\left(\Delta^{d} Y_{t}-Y_{t}\right)+\phi_{0} \sum_{i=1}^{p} \phi_{i} \Delta^{d} Y_{t-i}-\sum_{i=1}^{q} \theta_{i} \varepsilon_{t-i}+\varepsilon_{t}
$$

Where $\mathrm{d}$ corresponds to the $\mathrm{d}$ differences that are necessary to convert the original series to stationary, $\phi_{1}, \ldots$, $\phi_{p}$ are the parameters belonging to the "autoregressive" part of the model, $\theta_{1}, \ldots, \theta_{q}$ the parameters belonging to the "moving averages" part of the model, $\varepsilon_{t}$ is an error term and $\phi_{0}$ is a constant [15].

Taking into account that:

$$
\Delta Y_{t}=Y_{t}-Y_{t-1}
$$

It is a quantitative method in which the prediction is made based on the historical information we have available. This model is made up of three components: (AR) autoregressive, (I) integrated, and (MA) moving averages. For an ARIMA model (p, d, q) the parameters (p, $\mathrm{d}, \mathrm{q}$ ) must be determined with the most appropriate values. These will be non-negative integers.

First, an exploratory analysis of the data set has been performed. Subsequently, the detection of possible outliers was carried out. In those cases where outliers were present, they have been removed from the study. After cleaning the database, the object has been created for the time series. Its decomposition has been carried out in order to stabilize the variance, as well as to detect and eliminate the trend and seasonality. Finally, forecasting has been carried out through the ARIMA model, determining the optimal model.

The series modeled in this manuscript are, on the one hand, the number of minor injuries on Spanish roads; the movement of goods (in tons) transported by air; and the consumer price index of the transport sector, analyzed under the hypothesis of continuity of the current transportation model without introducing any changes. On the other hand, the evolution of GDP in the different study sectors, in this case, under the hypothesis of the entry into the market of autonomous vehicles.
According to what was stated in the introduction regarding the relevance that autonomous vehicles will have in the market, the particularization of the model in each of the study sectors is important (Section 3.2). It is necessary to identify different indicators that determine the variation of the model parameters and establish the trend of the prediction. This procedure has been applied to all the predictions made in the study. The results are presented in the next section.

\section{Results}

The results of the forecasts made using the ARIMA model and analysis of each sector affected by autonomous vehicles are featured below.

\subsection{Forecasting}

The variables selected for this study assume, among the available data, a representative sample of the current situation of the sector. In addition, they give us information on how the current scenario would progress if technological improvements in transport were not introduced. In the first case, the number of minor injuries on Spanish roads between January 1993 and December 2017 is analyzed. Road deaths have been reduced, above all, by the driving assistance systems incorporated in the vehicles and, moreover, by the controls established by the authorities. This does not mean, however, that accidents have decreased, but rather that they are less serious. For this reason, the variable minor injuries become relevant to this study. As we can see through Fig. 1, the prediction for this time series confirms a continued increase in the number of minor injuries on the roads.

Secondly, reference is made to air traffic statistics in Spain. The movement of goods (in tons) transported by air between January 2004 and August 2019 has been analyzed. This variable refers to the existing demand within the logistics sector in the airfield. In Fig. 2 we can see how the forecast is an uptrend. This means that, predictably, freight traffic will continue to increase, all of which is encouraged by e-commerce that, in the last decade has achieved a growth in the logistics sector globally. The increase in the transport of goods by air necessarily implies an increase in the transport of goods by land, in the distribution of medium and short distances Fig. 3.

Finally, a forecast for the consumer price index of the transport sector has been made (Fig. 3). The data cover the period from January 2015 to March 2019. The results indicate an uptrend. It should be taken into account that this kind of analysis is carried out only considering historical data and, therefore, does not take into account the influence of other independent variables within the forecast. We can interpret, for example, that the fact that the current transport model is 
FORECASTING

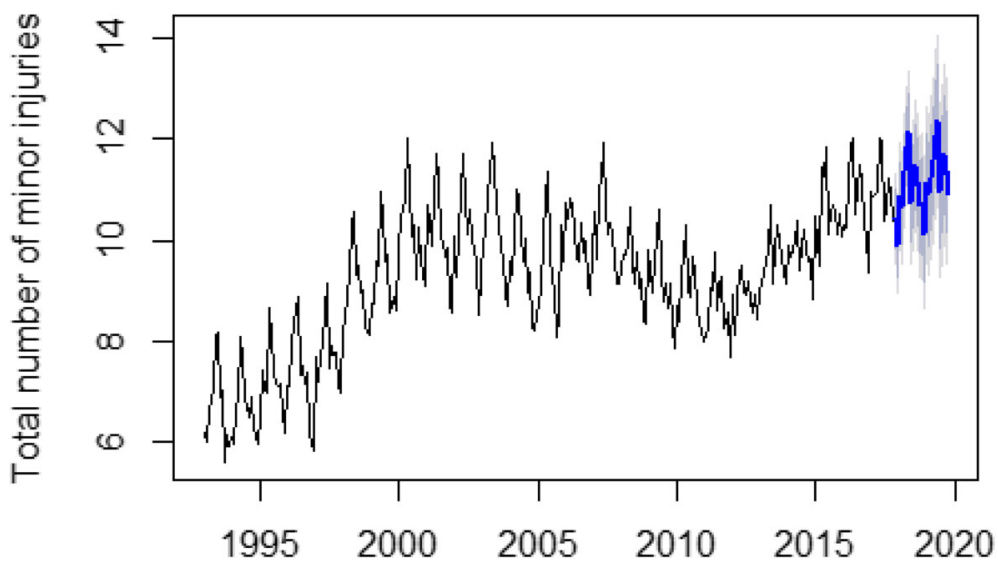

Fig. 1 The number of minor injuries on Spanish roads between January 1993 and December 2017

supported by fossil fuels with a limited life cycle, makes prices more expensive for the consumer. Not only that but having a vehicle owned is more expensive than having a mobility service on demand. With a new mobility service, on-demand consumers will have a more customized service while their waiting times will be reduced. This will lead to a greater willingness to move, as it is already mentioned, and will open the door to more flexible fees [16].

A strategic datum for making the forecasts of the impact on GDP in the different sectors is to determine the variation in the number of vehicles. In this case, the results obtained by applying the ARIMA method, described in Section 2, according to key variables and data collection, are presented in a table mode, to facilitate their understanding and observe the percentage variations in the three scenarios selected for the study. A progressive change can be seen in the configuration of the country's vehicle fleet. These results will be discussed in Section 3.2, part a.

Lastly, the summary of the forecasts of the evolution of the GDP in the analyzed industries is presented, obtained from the application of the ARIMA method as well, basing on the key variables which influence GDP: Consumption, investment public spending, and the framework of the three scenarios proposed: Inclusion of autonomous vehicles in GDP data for 1 . Inclusion of $20 \%$; 2 . Inclusion of $50 \%$; 3 . Inclusion of $100 \%$. As in the previous case, the results are presented in the below chart, Table 2, to obtain a

\section{FORECASTING}

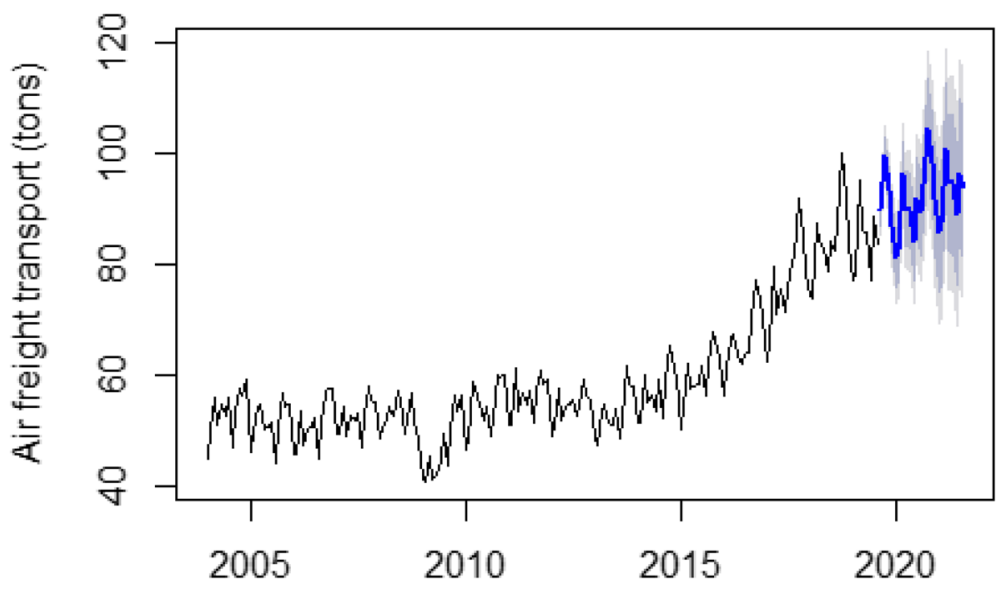

Fig. 2 The movement of goods (in tons) transported by air between January 2004 and August 2019 


\section{FORECASTING}

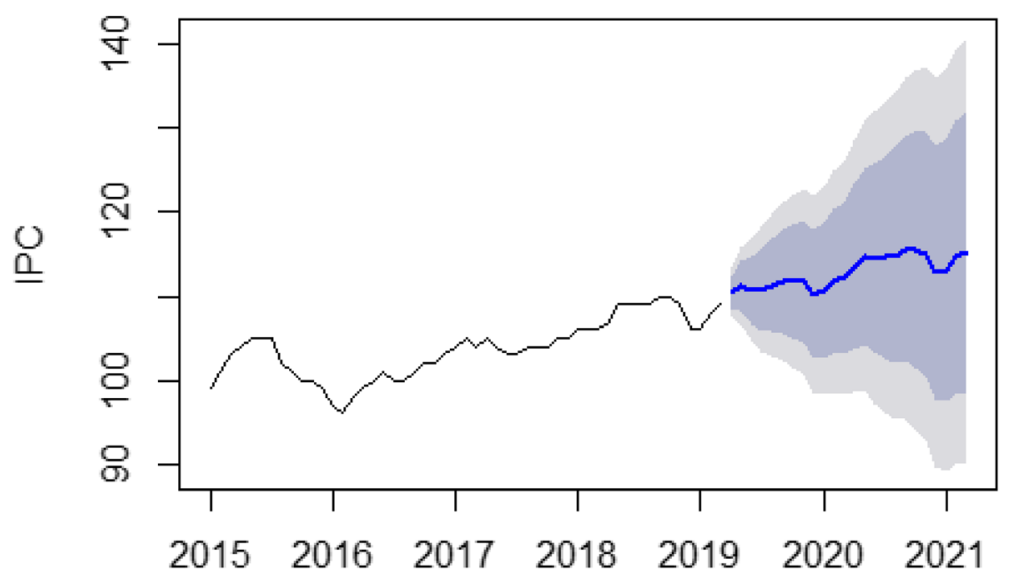

Fig. 3 The consumer price index of the transport sector between 2015 and 2019

complete vision of the evolution of the impact in the different sectors according to the growth of the market share that autonomous vehicles will represent. An important negative trend is observed in most of them, while others acquire greater relevance within GDP. See the case of goods transport, the technology industry, and passenger transport. Together these industries represent a $38,16 \%$ of Spanish GDP (€445.067,33 million). It is also important to highlight that in 2017, Spanish GDP was $€ 1,166,319$ million.

In order to conduct the forecast, the current GDP refers to the year 2017. Also, it is important to underscore that in the energy industry only the market of fossil fuels will be reduced in the percentages mentioned above.

All data has been collected from different Spanish public sources (INE, DGT, and Ministry of Public Works and Transport).

\subsection{Analysis of the different sectors 3.2.1 Automotive industry}

This section contains the analysis of the vehicle manufacturers. As we can see in Fig. 4, the current vehicle fleet has a positive trend. In other words, the vehicle fleet is increasing year by year and will continue to do

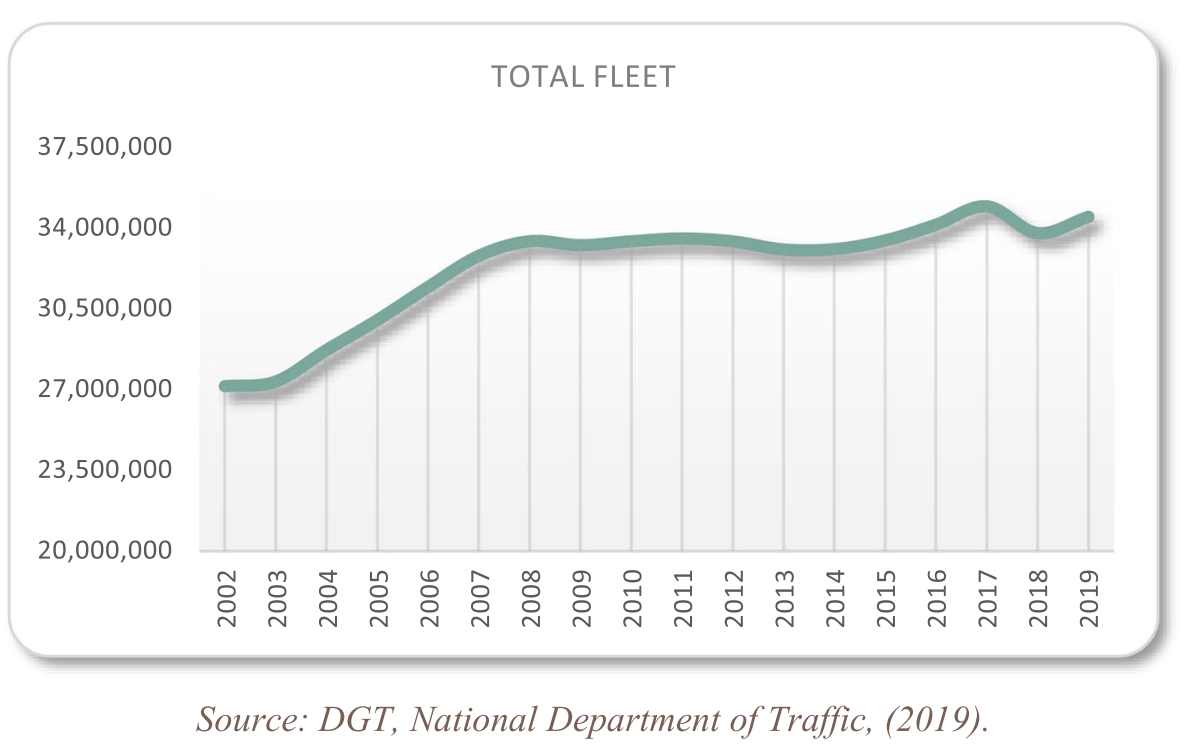

Fig. 4 The total vehicle fleet in Spain (2019 data) 
so. There is no surface available for this positive trend. Furthermore, if we try to put all of the vehicle fleets on the road at the same time, the collapse will be immediate. This is not a problem unique to Spain, but global. Total vehicle sales were 95 million vehicles around the world in 2018 [17]. If sales follow this positive trend, in 2020 , total vehicle sales will reach the number of 100 million vehicles, becoming in 2022 into 110 million vehicles all over the world.

This trend represents the current mobility model, based on private vehicles for the vast majority of trips, but it has come to an end. People demand new models of mobility, and technology offers a wide variety of solutions. Information and communication technologies have opened new solutions for urban mobility. There are new business models, such as ride-sharing services, on-demand services, or "transport as a service" (TaaS). Advocates predict that by 2030, within 10 years of regulatory approval of autonomous vehicles, $95 \%$ of U.S. passenger miles traveled will be served by on-demand autonomous electric vehicles owned by fleets, not individuals [18]. A recent MIT study of the taxi fleet in New York City shows an algorithm for a ride-sharing system, with a fleet of 2.000 taxis with a capacity of 10 people, which represents an $85 \%$ reduction of the current fleet (13.586) of taxis [19]. New trends in mobility will make ride-sharing services grow significantly and private cars decrease greatly.

These studies confirm the great decreasing trend in the number of private vehicles of the results presented in Table 1 . Trucks and vans fleet is going to decrease as it will be no longer necessary so many. Even if the freight market grows, one of the advantages of autonomous vehicles is that they can drive $24 \mathrm{~h}$ a day. In the same terms of efficiency, much of this transportation will be done at night to help better traffic distribution [20].

On the contrary, the busses fleet is going to increase as it has been doing for years, as Fig. 5 shows [21]. In the new models of ride-sharing on-demand mobility, new concepts of autonomous buses between 6 and 15 passengers will play a fundamental role.

In the case of motorcycles, they currently play an important role in urban mobility, due to their advantages in traffic jam situations. In an efficient mobility model of autonomous vehicles, its role loses importance. Users will opt for more comfortable mobility solutions, leaving motorcycles relegates to their lovers and hobbies.

Furthermore, new kinds of vehicles are going to appear. They will be single-person autonomous vehicles, for people with disabilities, small autonomous vehicles to make the purchase, among others.

Spain is one of the leading car producers in Europe. The current impact on the Gross Domestic Product of the sector is $10 \%$. The evolution of the automotive industry will be determined by the drastic reduction in the sale of private cars Fig. 6 .

\subsubsection{Equipment industry}

The automotive equipment and components industry is a very important sector in the country, even if its impact on GDP is lower. The reason is that, regardless of the automotive industry, equipment and components companies are Spanish and are not subsidiaries. As Fig. 7 states, they have a volume of a business near to $€ 35,000$ million. Its impact on the Spanish economy is $3 \%$ by GDP contribution [22].

Their export value is near $€ 19,510$ million in 2017 and it means to this industry an added value of $5,1 \%$, as is showed in Fig. 8.

Despite a drastic decline of the automotive industry, and the contracts they have with them, the equipment and components industry has greater capacity and flexibility to adapt towards a new mobility model.

The fall in the number of sales of private cars will affect the sector inevitably. However, autonomous vehicles will have higher replacement rates, because they will complete their life cycle in a shorter time. This industry has the capacity to establish new commercial links with the new manufacturing industry.

Its impact on the Spanish economy, according to the data presented in Table 2, is estimated at a decreased of $5 \%$ at the beginning of the transition, a $10 \%$ decreased during the middle of the transition and a final $16 \%$ decreased when the transition is completed, as Fig. 9 shows.

Table 1 The development of all vehicles fleet in the three different scenarios presented. The industrial tractor has not been analyzed in this study and VECs are a new vehicle model that is why there is no data available

\begin{tabular}{llllllcc}
\hline & $\begin{array}{l}\text { Current no } \\
\text { vehicles }\end{array}$ & Transition 20\% & No vehicles (T20\%) & Transition 50\% & $\begin{array}{l}\text { No vehicles } \\
\text { (T50\%) }\end{array}$ & $\begin{array}{c}\text { Transition 100\% } \\
\text { (T100\%) vehicles }\end{array}$ \\
\hline Trucks and vans & $4,924,476.00$ & $-8 \%$ & $4,530,517.92$ & $-15 \%$ & $4,185,804.60$ & $-32 \%$ & $3,348,643.68$ \\
Buses & $63,589.00$ & $12 \%$ & $71,219.68$ & $25 \%$ & $79,486.25$ & $48 \%$ & $94,111.72$ \\
$\begin{array}{l}\text { Passenger private } \\
\text { vehicles }\end{array}$ & $23,500,401.00$ & $-15 \%$ & $19,975,340.85$ & $-31 \%$ & $16,215,276.69$ & $-70 \%$ & $7,050,120.30$ \\
Motorcycles & $3,327,048.00$ & $-16 \%$ & $2,794,720.32$ & $-42 \%$ & $1,929,687.84$ & $-88 \%$ & $399,245.76$ \\
Industrial Tractor & $218,154.00$ & $218,154.00$ & $218,154.00$ & $218,154.00$ & $218,154.00$ & $218,154.00$ & $218,154.00$ \\
\hline
\end{tabular}




\section{TOTAL NUMBER OF BUSES}

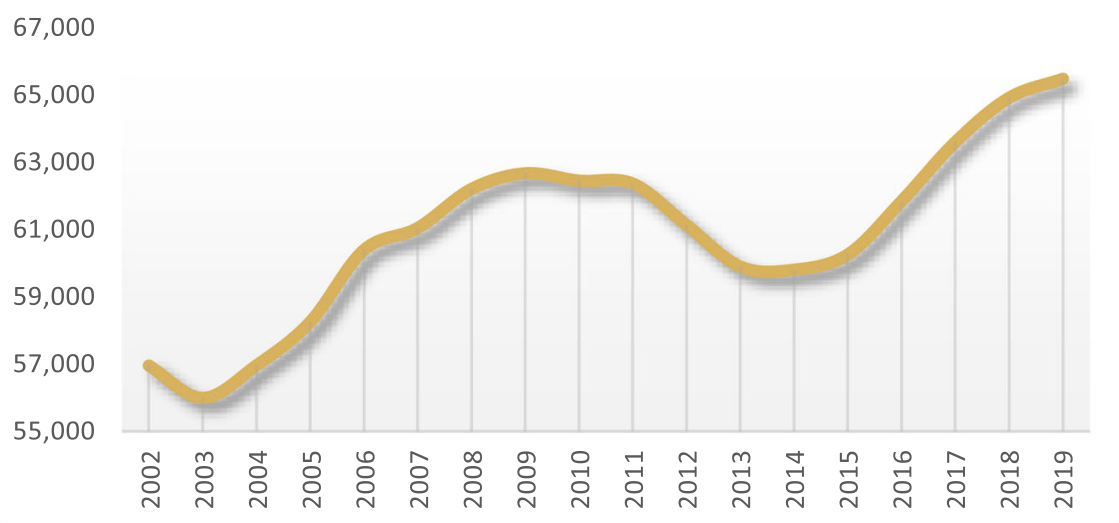

Source: INE, National Institute of Statistics, (2019).

Fig. 5 The total number of buses in Spain (2019 data)

\subsubsection{Goods transport}

One directly influenced industry by this new mobility model is the goods transport sector. It will greatly benefit in terms of security, in time, and costs.

Technology has made possible a new era where a driver is no need thus, mostly of trips will take place at night. If we add this and the real fact that ecommerce is increasing year by year [23], logistics will increase their effectiveness and their cost will be reduced.

People are buying more by the Internet increasing the number of goods that need to be transported that way goods transport will increase [24]. One of the needs of the sector is new autonomous vehicles designed for the last mile distribution for both urban areas and rural areas.

Taking into account the online shopping growth in Spain and all over the world, the logistics sector is an important industry in our economy. As Fig. 10 shows, it currently contributes $8 \%$ of GDP. At the beginning of the transition, it will not experience a sharp increase but as the evolution of transition progresses its increase will be bigger, increasing up to $58 \%$ when the transition is completed.

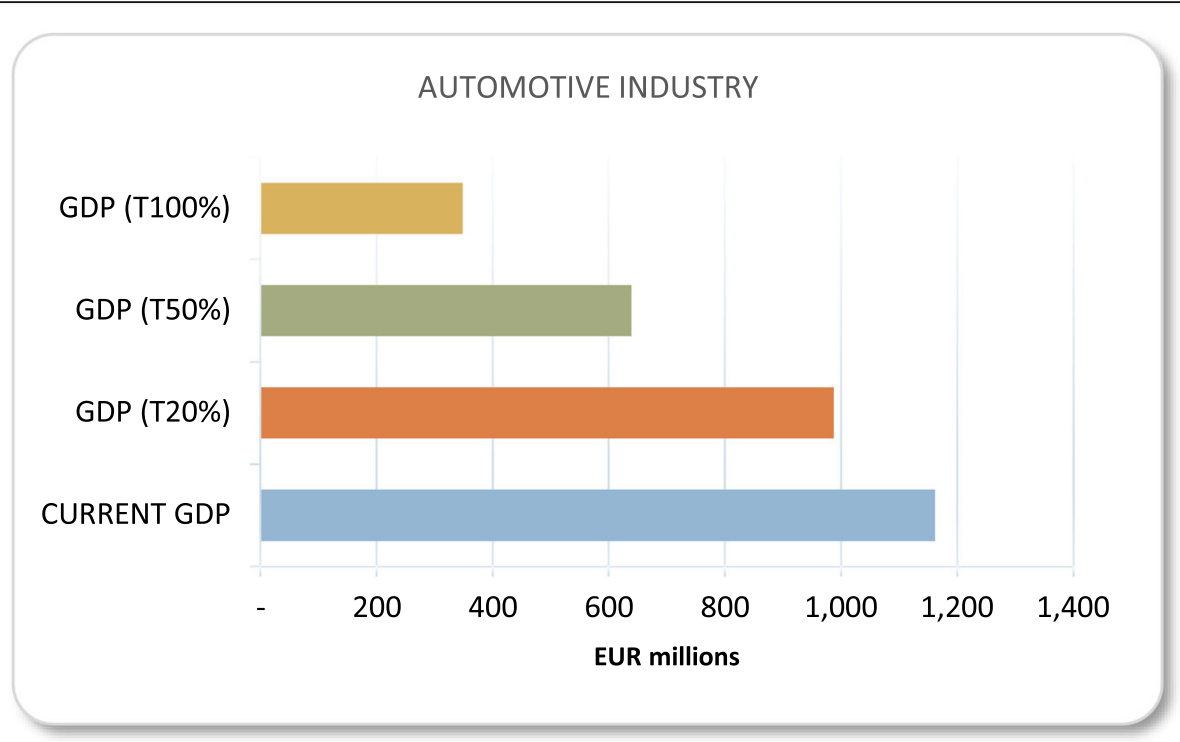

Fig. 6 Automotive Industry Spanish GDP forecast 


\section{BILLING (mill€)}

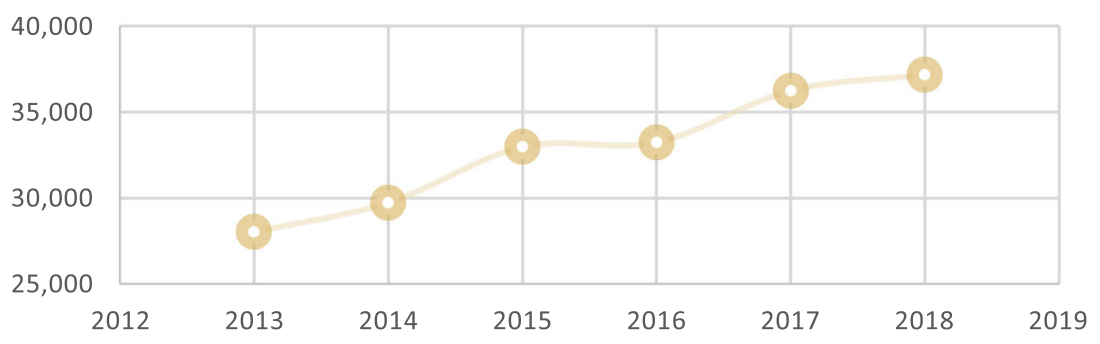

Source: SERNAUTO, the Spanish association of auto suppliers.

Fig. 7 Billing of the Spanish equipment industry

\subsubsection{Passenger transport}

The great beneficiaries of the new mobility model will be users, the people. And it is the main reason for this revolution, to improve the quality of life of our society. Currently, it is estimated that a person average travel in Spain is $41,6 \mathrm{~km}$ per day [25]. With an autonomous mobility system, a new range of possibilities opens up for people who cannot use a vehicle, such as minors or the elderly, in addition to facilitating the possibilities of displacement in situations where it is tedious to move in a city due to traffic jams or parking. For these reasons, we estimate that this average distance per person will increase notably, it could double. In many cases, people do not move because they do not have an efficient mobility solution, or there are many inconveniences, such as parking, taxes, congestion, etc.
As Fig. 11 shows, currently, most of these travels are made in private vehicles [26]. The reality is that on many occasions the private vehicle is the only mobility solution. The new on-demand autonomous mobility model will bring these existing alternatives that do not exist today.

Technology is evolving and the concern for the environment and our health is also increasing. These concerns push into a change in our current way of moving that brings a new on-demand and shared services. Mobility will be cheaper, safer, and more efficient. This will allow higher displacements and will transform the current way of moving into an eco-friendly way of moving.

Current passenger transport contributes $8 \%$ of GDP, maintaining at the beginning of the transition, increasing to $25 \%$ in the middle and ending with an increase of $55 \%$ Fig. 12.

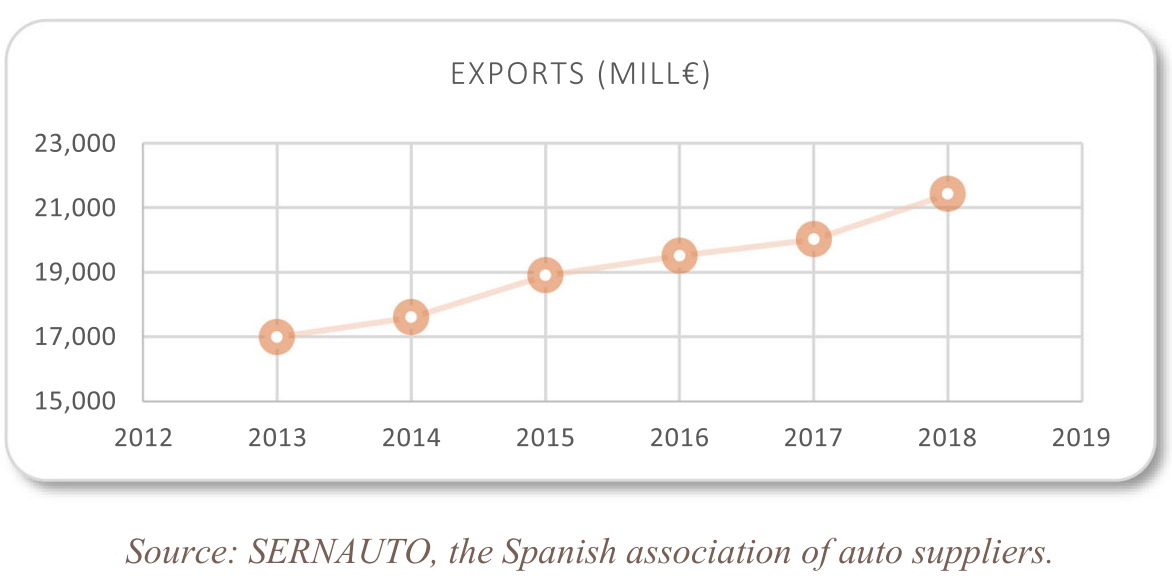

Fig. 8 The exports of the Spanish equipment industry 
Table 2 GDP Forecast of all the industries analyzed along with this paper with the three scenarios proposed and their related GDP data in millions of euros

\begin{tabular}{|c|c|c|c|c|c|c|c|c|}
\hline & $\begin{array}{l}\text { Current } \\
\text { GDP }\end{array}$ & $\begin{array}{l}\text { Current } \\
\text { GDP }\end{array}$ & $\begin{array}{l}\text { Transition } \\
20 \%\end{array}$ & $\begin{array}{l}\text { GDP } \\
\text { (T20\%) }\end{array}$ & $\begin{array}{l}\text { Transition } \\
50 \%\end{array}$ & $\begin{array}{l}\text { GDP } \\
\text { (T50\%) }\end{array}$ & $\begin{array}{l}\text { Transition } \\
100 \%\end{array}$ & $\begin{array}{l}\text { GDP } \\
\text { (T100\%) }\end{array}$ \\
\hline Equipment industry & $3 \%$ & $35.805,99 €$ & $-5 \%$ & $34.015,69 €$ & $-10 \%$ & $32.225,39 €$ & $-16 \%$ & $30.077,03 €$ \\
\hline Goods transport & $8 \%$ & $93.305,52 €$ & $9 \%$ & $101.703,02 €$ & $26 \%$ & $117.564,96 €$ & $58 \%$ & $147.422,72 €$ \\
\hline $\begin{array}{l}\text { No-life insurance } \\
\text { industry }\end{array}$ & $0.90 \%$ & $10.496,87 €$ & $-5 \%$ & $9.972,03 €$ & $-50 \%$ & $5.248,44 €$ & $-65 \%$ & $3.673,90 €$ \\
\hline Professionals concerned & $0,27 \%$ & $3.149,06 €$ & $-10 \%$ & $2.834,16 €$ & $-44 \%$ & $1.763,47 €$ & $-85 \%$ & $472,36 €$ \\
\hline Technological industry & $1.20 \%$ & $13.995,83 €$ & $25 \%$ & $17.494,79 €$ & $80 \%$ & $25.192,49 €$ & $160 \%$ & $36.389,15 €$ \\
\hline Health & $1 \%$ & $11.663,19 €$ & $-23 \%$ & $8.980,66 €$ & $-60 \%$ & $4.665,28 €$ & $-90 \%$ & $1.166,32 €$ \\
\hline Passenger transport & $8 \%$ & $93.305,52 €$ & $8 \%$ & $100.769,96 €$ & $25 \%$ & $116.631,90 €$ & $55 \%$ & $144.623,56 €$ \\
\hline Energy industry & $2.50 \%$ & $26.242,18 €$ & $-24 \%$ & $19.944,05 €$ & $-55 \%$ & $11.808,98 €$ & $-98 \%$ & $524,84 €$ \\
\hline $\begin{array}{l}\text { Repair and maintenance } \\
\text { industry }\end{array}$ & $3,47 \%$ & $40.471,27 €$ & $-3 \%$ & $39.257,13 €$ & $-10 \%$ & $36.424,14 €$ & $-15 \%$ & $34.400,58 €$ \\
\hline Automotive industry & $10 \%$ & $116.631,90 €$ & $-15 \%$ & $99.137,12 €$ & $-45 \%$ & $64.147,55 €$ & $-70 \%$ & $34.989,57 €$ \\
\hline TOTAL & $38,16 \%$ & $445.067,33 €$ & - & $434.108,60 €$ & - & $415.672,59 €$ & - & $433.740,04 €$ \\
\hline
\end{tabular}

\subsubsection{No-life insurance industry}

The No-life insurance industry (insurance industry less life insurance), especially the ones related to automotive, will be greatly affected. This relationship is mainly due to two factors: the drastic reduction in the fleet of vehicles, which implies that much less insurance will be hired, and the reduction in the number of accidents.

However, it is important to highlight that automotive insurance will have an important boom before its fall. This is due to an experimental phase that will conduct all the autonomous vehicles before their freecirculation and certification process. This will take place at the beginning of the transition, where the insurance of an autonomous vehicle will be more expensive.

Likewise, another key point to explain this negative trend in the automotive insurance industry: Autonomous vehicles will reduce dramatically the accident rate, thanks to the removal of the human factor (a major cause of the accidents). In other words, a cut on the accident rate will suppose a decrease in cost insurance and insurance premiums, decreasing proportionally their benefit. Insurance rates go lower as less traffic translates to fewer accidents.

If we translate that information into data, it is obtained that the automotive insurance industry contributes

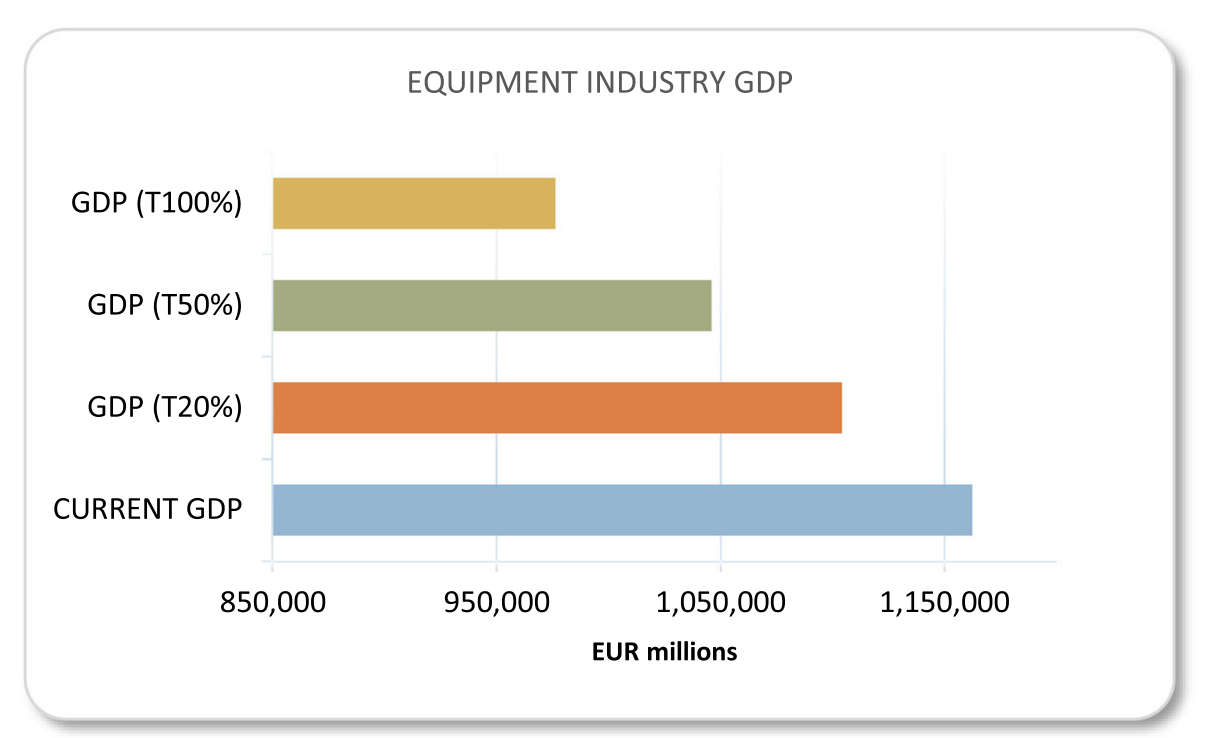

Fig. 9 GDP forecast of the Spanish equipment industry 


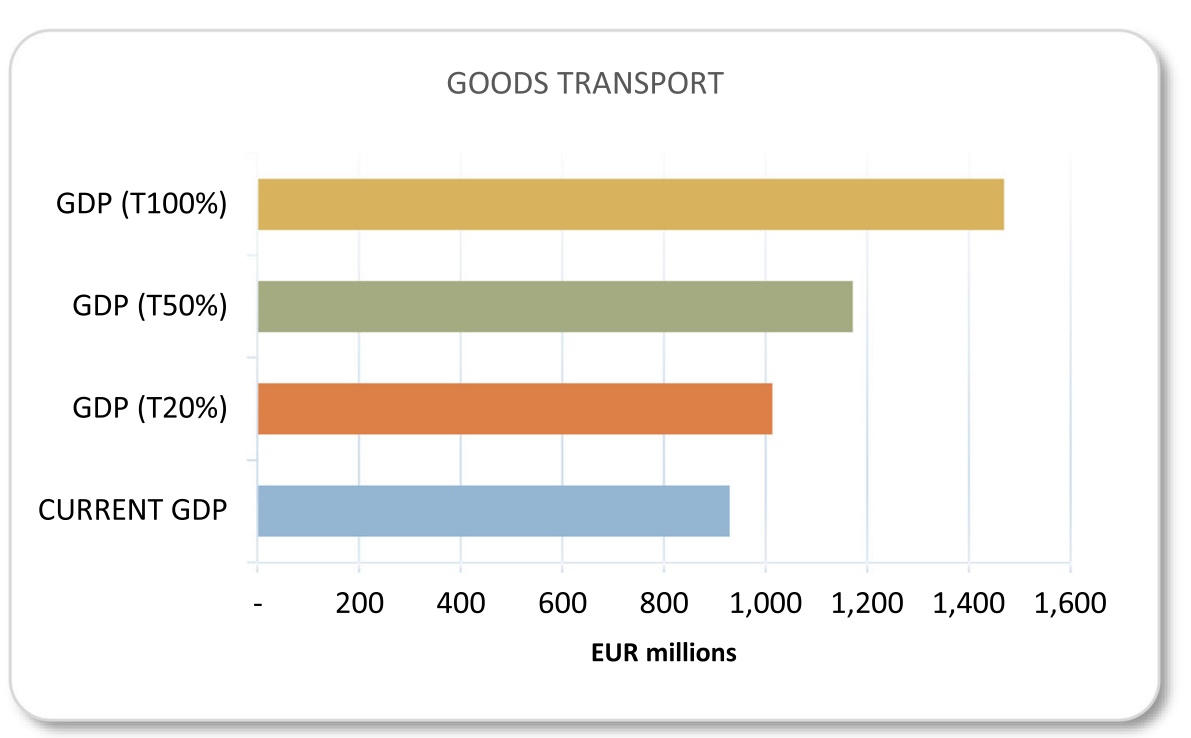

Fig. 10 Spanish GDP forecast for the goods transport industry

about $0,9 \%$ of GDP. Its drop will be 5, 50, and $65 \%$ respectively to each scenario Fig. 13.

\subsubsection{Repair and maintenance industry}

Inside this sector are encompassed workshops and repair and maintenance vehicles centers [27]. They will suffer big changes and will be affected directly by the intrusion of autonomous mobility. The vehicle repair market will be strongly affected due to a decrease in traffic accidents mentioned before. The maintenance vehicles market will remain to be necessary though it will be subject to important changes. Currently, this sector contributes a 3,5\% to GDP. At the beginning of the transition, it will decrease a $3 \%$ it will continue to fall until $15 \%$.

New autonomous vehicles will increase their circulating time which means the necessity of regular reviews to complete their routes in perfect shape. Autonomous vehicles will be intelligent tanks to their AI will know when they need a review. Many workshops could retrain and carry out vehicle supervision and vehicle review [28]. In other words, play as fleet operators, who will take a great part in the current market.

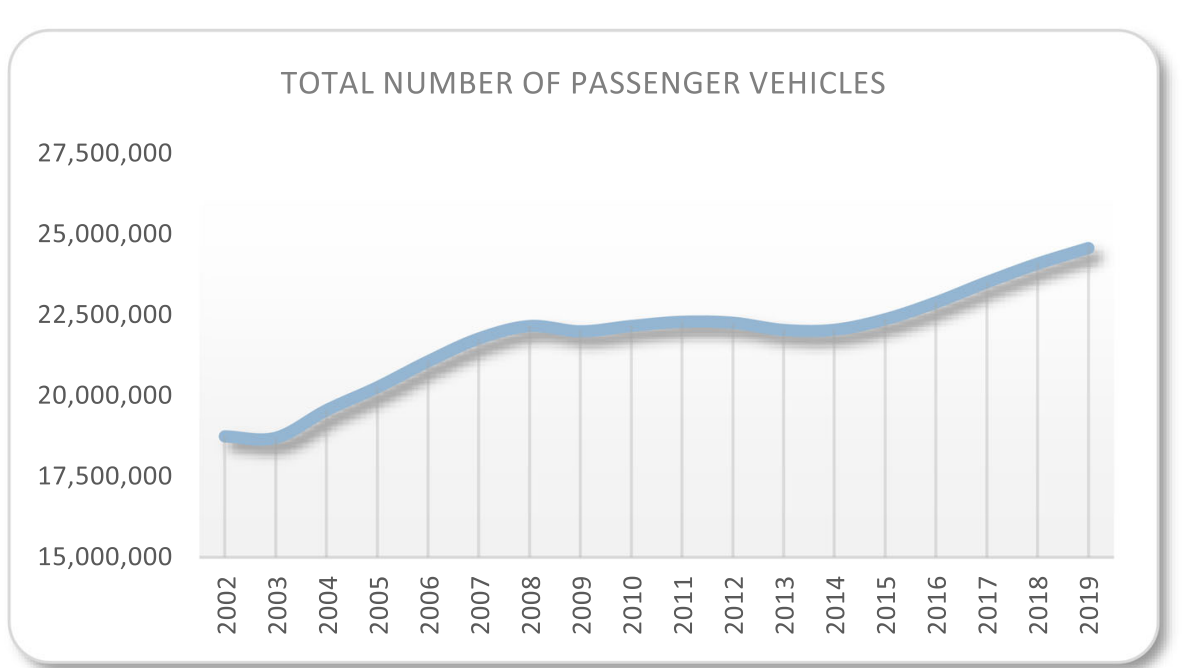

Source: DGT, National Department of Traffic, (2019)

Fig. 11 The total number of passenger vehicles in Spain (2019 data) 


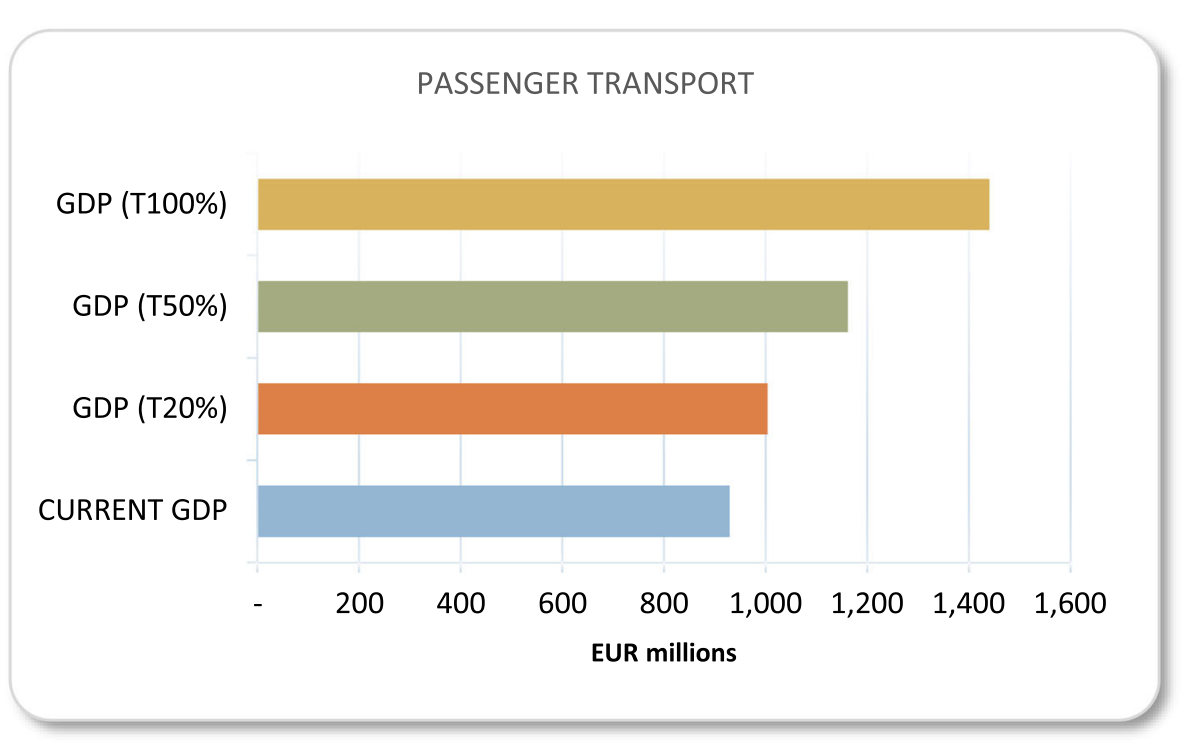

Fig. 12 GDP forecast for Spanish passenger transport

\subsubsection{Professional concerned}

This sector brings together driving professionals. One of the most outstanding features of an autonomous vehicle is that it does not need a driver. The trend in this sector is evident. Drivers are a profession that will disappear. It is very important to bet on the professional transformation of these people, to avoid great social dramas. However, some companies with ride-sharing mobility services will opt for on-board assistants for the passengers in the first stages of the transition. It is a professional profile of easy conversion.
At the beginning of the transition, a big change is not going to be distinguished. It is only expected a drop of $10 \%$ by GDP, more or less a proportional reduction of the vehicle fleet. Later stages will have a huge change. A reduction of $44 \%$ by GDP and a decrease of $85 \%$ by GDP at the end of the transition.

\subsubsection{Technological industry}

Autonomous and electric vehicles are very different from conventional ones. Hardware and software have an important role in these new vehicles, and therefore, there

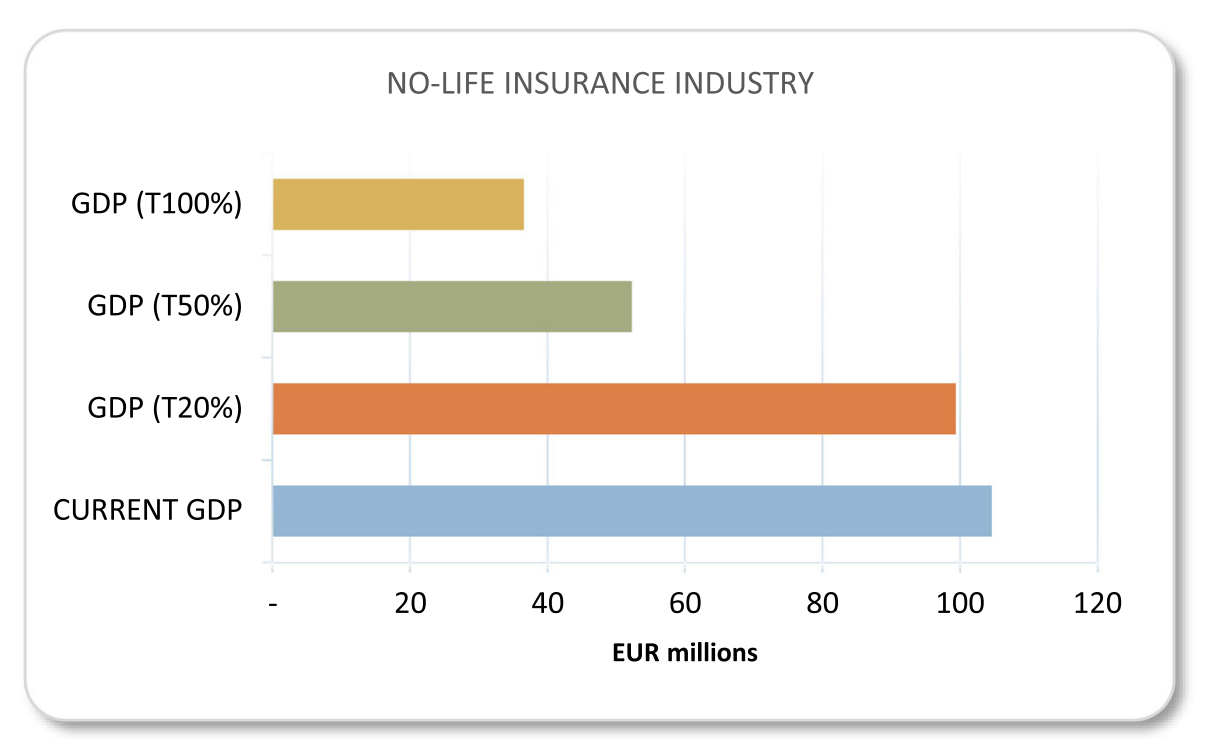

Fig. 13 GDP forecast of the Spanish no-life insurance industry 


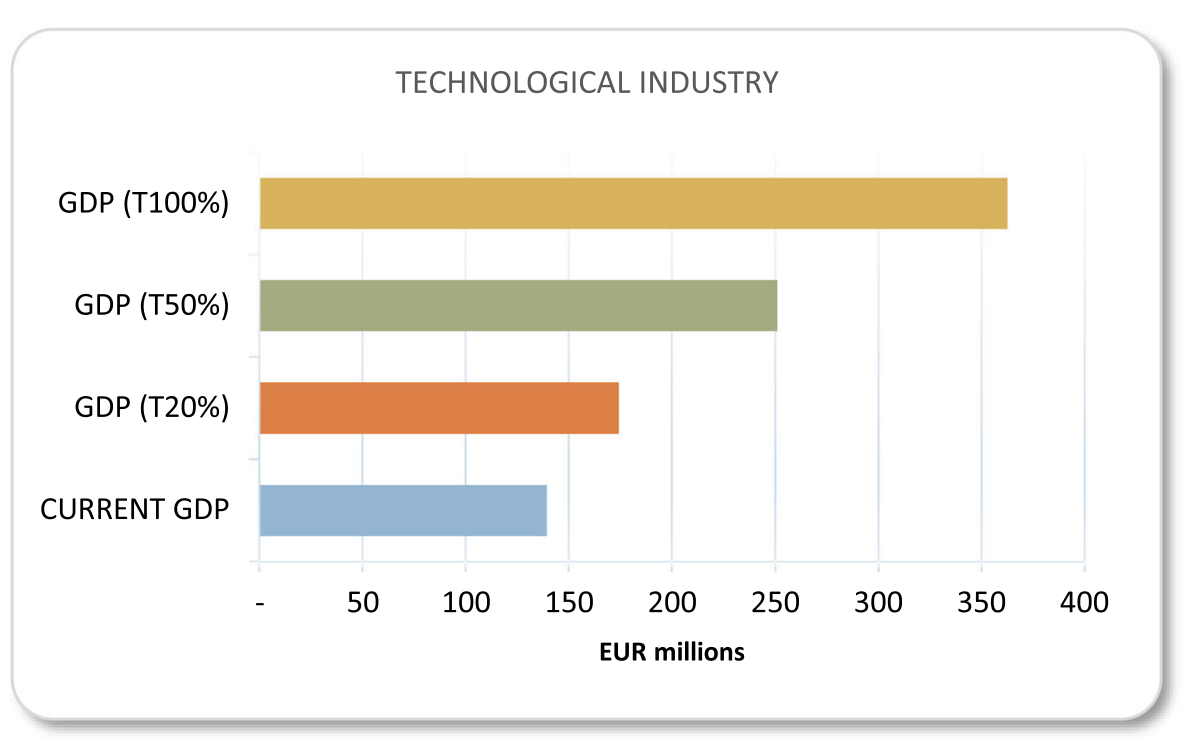

Fig. 14 GDP forecast of the Spanish technological industry

also will be great changes in the professionals who design them.

The automotive industry has to face a process of conversion, both technological and professional, which will require great financial efforts. A strong crisis is expected in the sector. On the other hand, an emerging industry has a simpler process, it only requires investment for research and development. Some of the most prominent actors in this new market will be emerging technology companies.

There will also be new business models that do not exist today. For example, telecom operators to service autonomous vehicles through V2X communications, or autonomous traffic management, through AI and Big Data techniques.
A new era where AI plays a critical role. This new technological sector requires a high investment at R\&D, which means an important competitive advantage to the country. It is a great opportunity for Spain to position itself in this sector and bet for this GDP increase.

In terms of data, this sector contributes directly to GDP by $€ 13,995$ million (1.2\%) and it employs over 219, 234 people (1.3\%) Fig. 14.

\subsubsection{Health}

Traffic accidents are a huge social drama. In addition to the fatalities, there are thousands of wounded every year, and many times we forget them. The medical services for all these people are a great economic cost for the country.

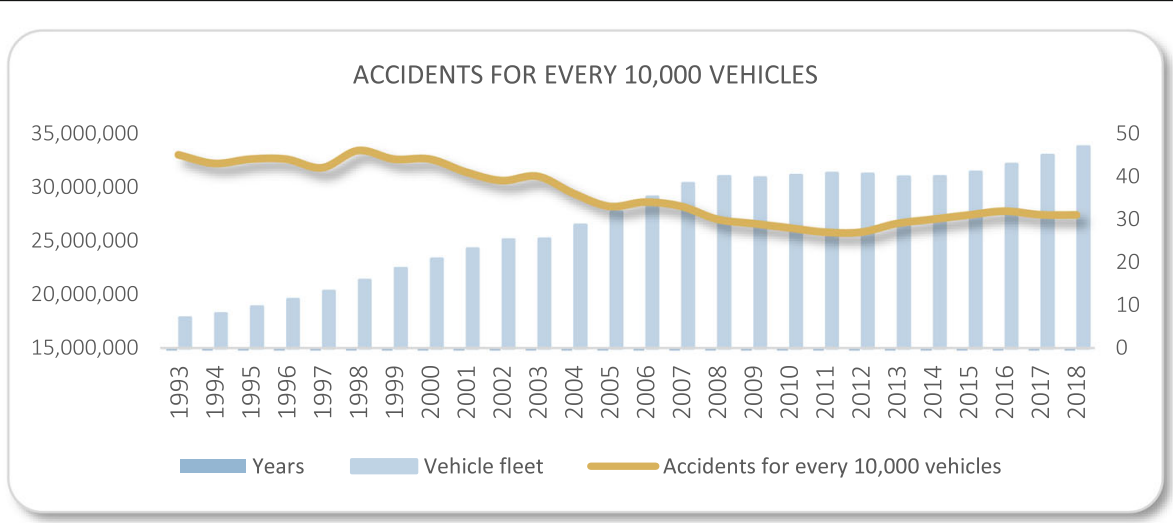

Source: DGT, National Department of Traffic, (2018).

Fig. 15 The accident number in Spain per 10,000 vehicles 


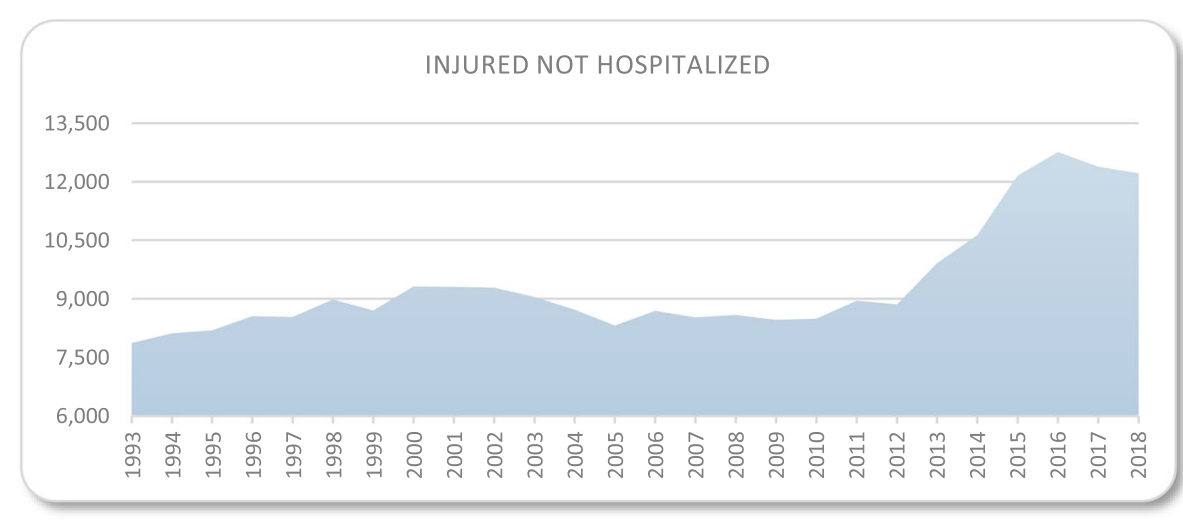

Source: DGT, National Department of Traffic, (2018).

Fig. 16 The Number of injured not hospitalized in Spain (2018 data)

As Fig. 15 shows the rate of accidents has been reduced. The number of accidents has been reduced considerably in the last 20 years. But there comes a point where the figure stabilizes and it is very difficult to reduce it, due to the human factor, we are not perfect drivers. Autonomous driving technologies will solve this problem.

Although mortal accidents have decreased, it is important to point out that the number of injured not hospitalized has increased, as can be seen in Fig. 16. Due to technological development, there have been considerable medical advances that allow more survivors.

Another important point is that the main factor behind traffic accidents is the human factor. It will be eliminated with a reduction in the vehicle fleet and their replacement by autonomous ones. Spain has a high accident rate. This change will suppose high cost-savings in health care and a decongestion in health service.

In data terms, at the beginning of the transition, a decrease of $23 \%$ is expected, becoming a $-60 \%$ in the middle and ending by a decrease of $90 \%$ Fig. 17.

\subsubsection{Fossil fuels}

The great success of the combustion vehicles during the last century has made the fossil fuel market become one of the most powerful.

In Figs. 18 and 19 gasoline and gasoil vehicles, fleet evolution can be seen. Although gasoil vehicles have a positive trend, nowadays people prefer gasoline, due to being less polluting.

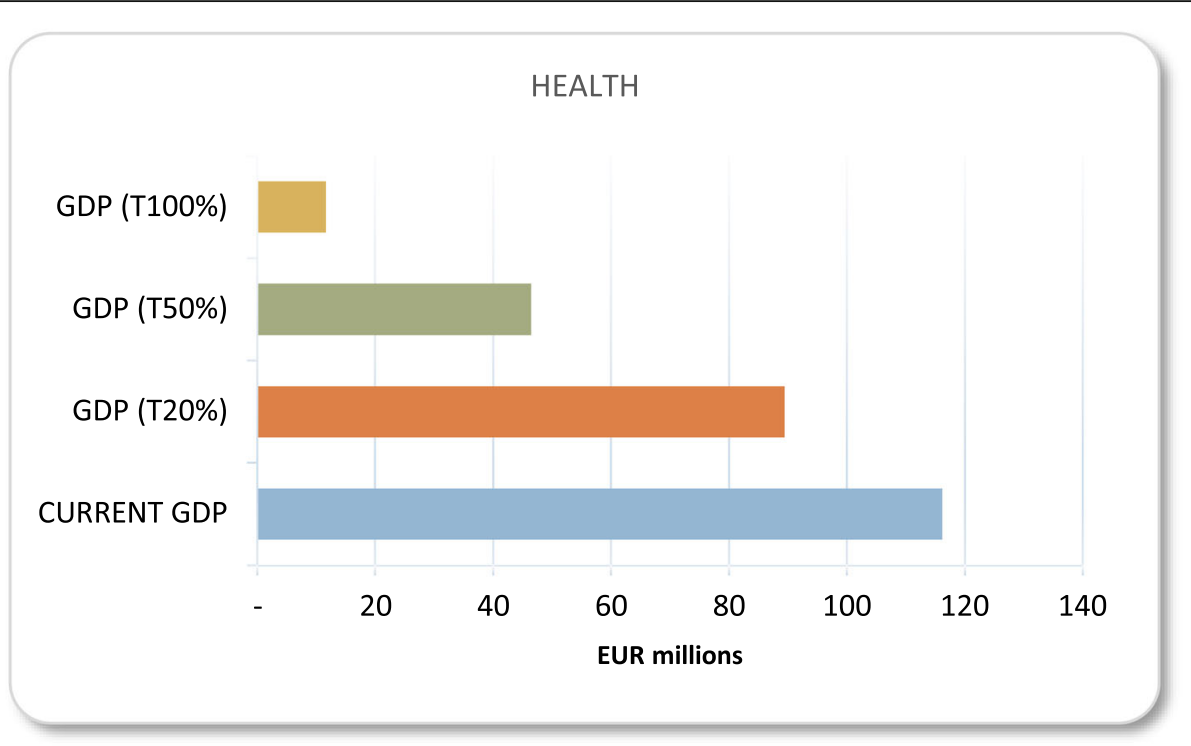

Fig. 17 GDP forecast of the Spanish health industry 


\section{TOTAL GASOLINE VEHICLES}

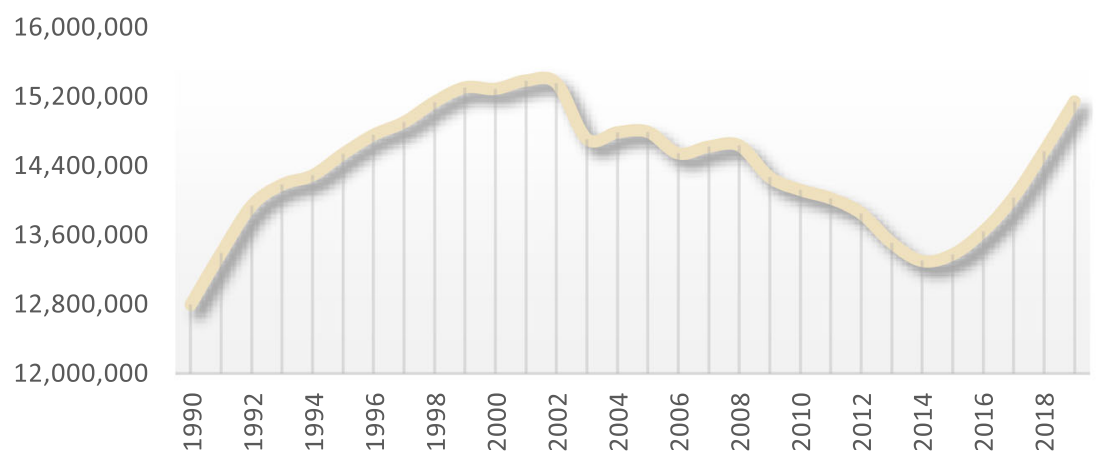

Source: DGT, National Department of Traffic, (2019).

Fig. 18 Total gasoline vehicles fleet in Spain (2019 data)

The emergence of new clean propulsive systems has put this market in check. There is one very clear issue, people's health is above any business model, no matter how powerful or consolidated it may be. Different governments in the world are already taking action Fig. 20. Spain announced the prohibition of combustion vehicles by 2040 .

The conventional fossil fuel market will come to an end. It will be replaced by a new energy market, not negligible. Electric vehicles will be the majority, but we must not rule out other forms of clean propulsion, such as hydrogen or new successful research.

Currently, sector billing data are $€ 30.000$ million. The fossil fuel market will greatly decrease. In the beginning, it will decrease by $24 \%$ turn into $55 \%$ in the middle, and $98 \%$ at the end of the transition, according to the data presented in Table 2 . It will be an abrupt decrease directly associated with the decrease of the combustion vehicle fleet Fig. 21

Fossil fuel will still be necessary till the New Era of Transportation extend to maritime and air transport. Also, it will be necessary as a stand-energy in cases of force majeure and.

\subsubsection{Infrastructure}

The country's infrastructure plays a very important role in transportation and autonomous mobility. Spain has a very high-quality road network and good connections. The new mobility model does not require the construction of new infrastructure, there may be some exceptions. However, what it does require is an adaptation of

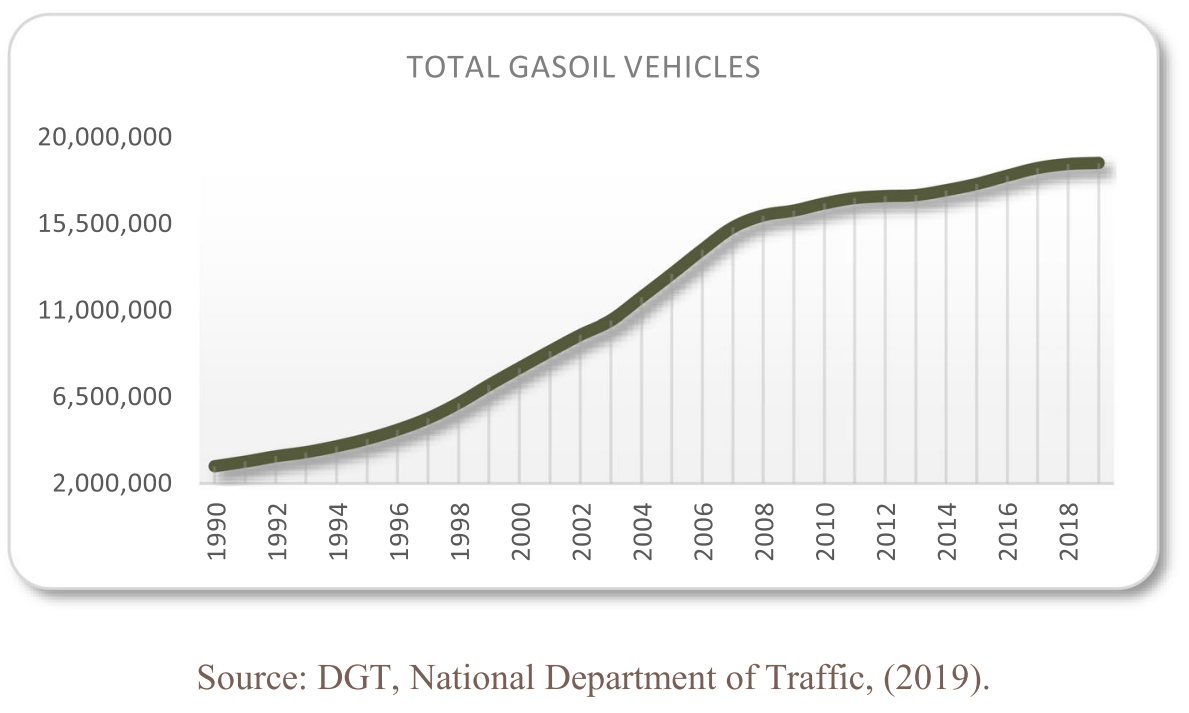

Fig. 19 Total gasoil vehicles fleet in Spain (2019 data) 


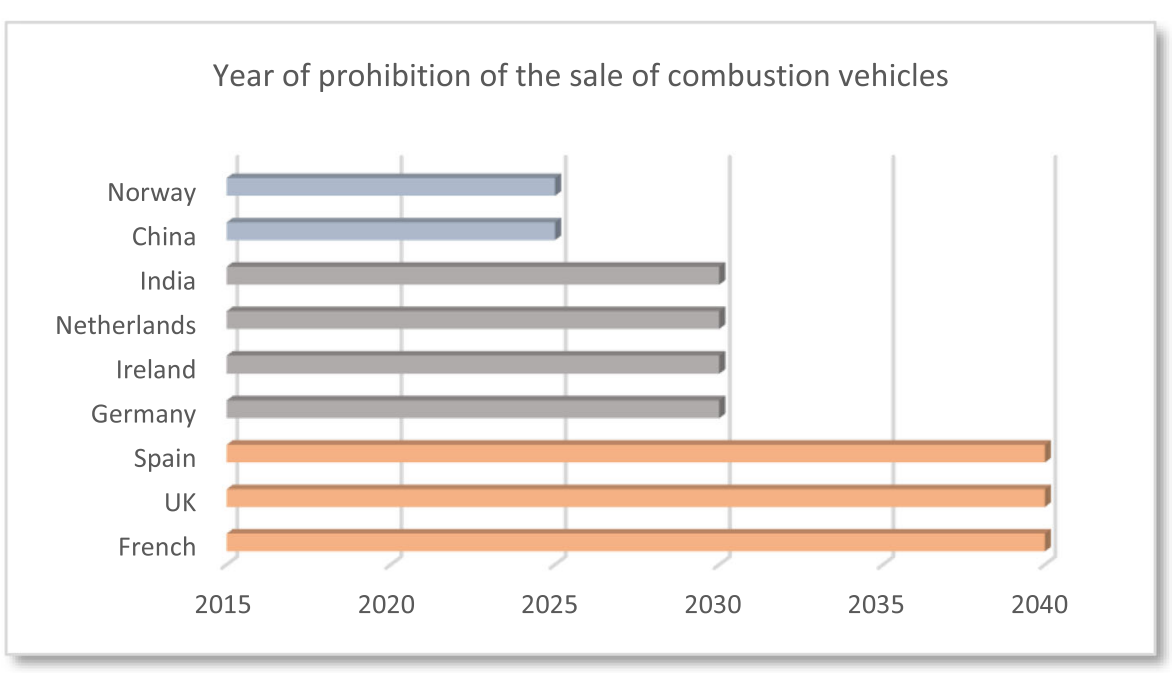

Fig. 20 Year of the prohibition of the sale of combustion vehicles

the existing infrastructure. It is necessary to add the intelligence layer to the current road network, a process known as 'technification'. It is a process that consists of adding different elements that allow creating a secure V2X network nationwide. All existing routes may be reusable and are suitable for technification. This technification will allow us to convert these roads into smart roads where autonomous vehicles can circulate.

In financial terms, this is a great advantage over other technologies that require much higher investments at the national level. Maintenance costs will be maintained, and it will be very important to devote great attention to them.
As it can be seen in Fig. 22, technification cost is about twenty times lower than conventional road construction cost, and even forty times smaller than a highway construction cost.

\subsubsection{Urbanism}

The new era of transportation brings a new conception of cities. In the beginning, cities were designed for cars, as an exclusive item, which nowadays turns on a common item. A restructuring of cities is needed: The reduction of the vehicle fleet and the optimization of traffic flows will allow redefining a lot of space occupied

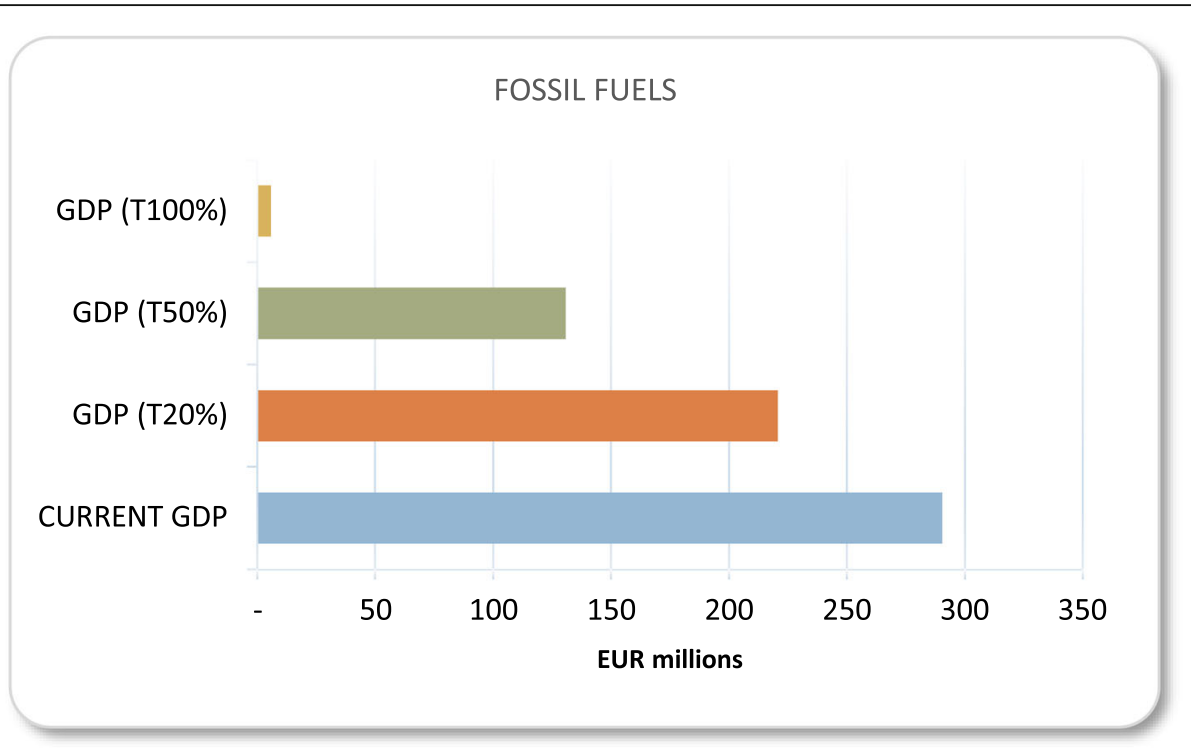

Fig. 21 GDP forecast of the Spanish fossil fuels energy industry 


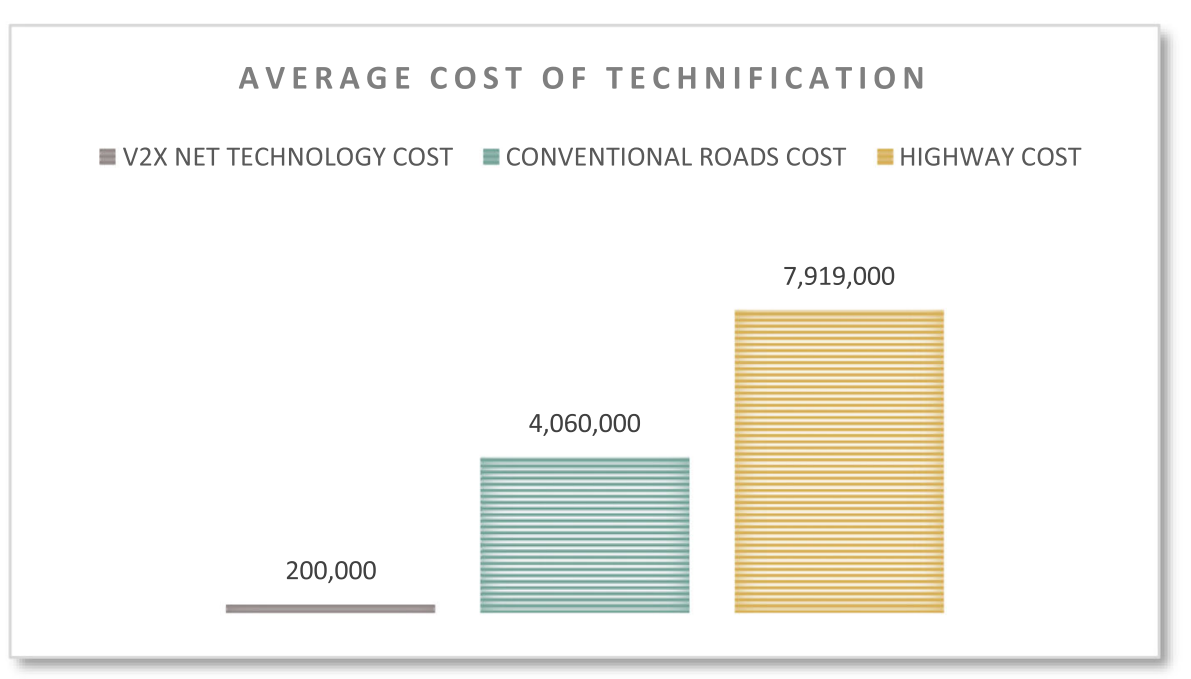

Fig. 22 The average cost of technification a road in Spain

today. In short, cities will be recovered for citizens, as a great civic asset.

Urban planning is a sector with a good growth forecast due to the consequences of autonomous mobility. Many of the city spaces occupied by vehicles, such as parking lots, will be converted into green-spaces or other assets that prioritize social welfare. In other words, these businesses will have to readapt cities to sustainable and Smart cities and bring technology closer to social welfare. Nowadays there are already many companies around the world working on it, such as Burohappold engineering, HRA, KPF, among others.

E-commerce creates the need to build numerous logistic centers in urban areas to satisfy the great demand for home delivery. This will be a very interesting business for the sector. Another of the urban consequences of autonomous mobility is the design of buildings with new functionalities. The last mile distribution with autonomous vehicles generates new needs, for example, a specific elevator for goods, either from the ground or from the roof (there will also be autonomous drones).

\section{Conclusions}

Autonomous vehicles are in the last stages of technological development, with their entry into the market ever closer. This manuscript aims to analyze from a global point of view the impact of this phenomenon on the Spanish economy.

Firstly, it is mandatory that governments start preparing a step-by-step plan at an economic, technological, and social level, which allow enterprises to prepare themselves for autonomous vehicles inclusion. Furthermore not only for businesses but for governments also to take appropriate measures from the start. Big investments would be needed, but preparing in advance for this change will allow any country to be placed as one of the leaders in this revolution. This plan will be a key point for the adaptation and survival of all industries affected to minimize damage and avoid social dramas. To make this possible, a long-term study needs to be carried out because analyzing only the early stages of the transition brings a lost in the global perspective of the change.

Secondly, the way we live today and the way we move will be totally changed. Transportation will transform into a model based on fleet operators with on-demand ride-sharing services affecting in a current mobile park. The decrease in the number of private vehicles and an increase in those for shared use, the direct consequence is a benefit for widespread traffic efficiency. Accidents will be decreased, as well as the movement of freight transport and consumer price index, translating into a lower cost for citizens. The new mobility model may offer cheaper solutions that we have today The revolution could be summed up in a model of safe, sustainable, and efficient mobility, with more disposable income per inhabitant.

Thirdly, it is very difficult to find a commercial or economic activity that is not affected to a greater or lesser extent by this change. The automotive industry and the oil industry are the most affected in macro terms by this revolution. Their business models are reaching a turning point, and although they have been protecting by governments over time, they have already assumed that they must act. Undoubtedly, the health and safety of people are above commercial interests. 


\section{Abbreviations}

NERTRA: New era of transportation; NLP: Non-Law Proposition; ARIMA model: Autoregressive integrated moving average model; MaaS: Mobility as a service; GDP: Gross Domestic Product; R\&D: Research and Development; DGT: National Department of Traffic; INE: National institute of statistics; V2X: Vehicle to everything communications; Al: Artificial intelligent

\section{Acknowledgments}

The authors thank the results of this study to the DROTIUM team for the support received during its development, and respective research groups of the University of León that have collaborated.

\section{Authors' contributions}

EF: He was leading the research team. He wrote the article with the data and contributions provided by the following authors. CA: She was in charge of the treatment of the data in the study and the realization of the numerical forecasts. MG: She was in charge of the data collection process and the analysis of this data and the impact factors in the different sectors analyzed. RF: He was responsible for reviewing the article and advised on changes. MN: He was responsible for reviewing the article and advised on changes. All authors read and approved the final manuscript.

\section{Funding}

This research project was financially supported by a private company, Drotium.

\section{Availability of data and materials}

The datasets used and/or analyzed during the current study are available from the corresponding author on reasonable request.

\section{Competing interests}

The authors declare that they have no competing interests.

\section{Author details}

${ }^{1}$ Drotium, a Mobility Company, Avenida de los Jesuitas 13, 24007 León, Spain. ${ }^{2}$ University of León, School of Industrial Engineering and Information Technology, Campus de Vegazana s/n, 24071 León, Spain. ${ }^{3}$ University of León, Economy and Business Management, Campus de Vegazana s/n, 24071 León, Spain.

\section{Received: 15 January 2020 Accepted: 20 October 2020}

Published online: 31 October 2020

\section{References}

1. Thurn, S., P. M. S., Montemerlo, M., Dahlkamp, H., Stavens, D., Aron, A., .. Christia (2006). Stanley: the robot that won the DARPA grand challenge. Journal of Field Robotics, 23(6), 661-692.

2. Waymo (2018). Millions of miles driven. [Online]. Available: https://waymo. com/ontheroad/. Accessed 17 Apr 2018.

3. Guerreiro, C., Ortiz, A. G., de Leeuw, F., Viana, M., Horálek, J. (2016). Air quality in Europe-2016 report. Publications Office of the European Union.

4. Directorate General for Traffic (2016). Las principales cifras de la SIniestralidad Vial España 2016.

5. WHO (2013). Global status report on road safety 2013, (pp. 1-12). Geneva: World Health Organization.

6. U.S. Department of and N. H. T. S. A. Transportation (2008). National motor vehicle crash causation survey report to congress.

7. Cookson, G., \& Pishue, B. (2018). INRIX global traffic scorecard.

8. European Environment Agency (2016). Electric vehicles in Europe.

9. Fagnant, D. J., \& Kockelman, K. (2015). Preparing a nation for autonomous vehicles: opportunities, barriers and policy recommendations. Transportation Research Part A: Policy and Practice, 77, 167-181.

10. Manyika, J., Chui, M., Bughin, J., Dobbs, R., Bisson, P., \& Marrs (2013). Disruptive technologies: Advances that will transform life, business, and the global economy, (p. 163). New York: McKinsey Global Insitute.

11. Lanctot, R. (2017). Accelerating the future: the economic impact of the emerging passenger economy autonomous. Autonomous Vehicles Services, no. June, pp. 1-30.

12. D. G. de T. (DGT) (2015). Instrucción 15N-113: Autorización de pruebas o ensayos de investigación realizados con vehículos de conducción automatizada en vías abiertas al tráfico en general.
13. C. de C. y León. (2019). Ley 9 / 2018, de 20 de diciembre, de transporte público de viajeros por carretera de Castilla y León. Sapin, pp. 1-42.

14. Clements, L. M., \& Kockelman, K. M. (2017). Economic effects of automated vehicles. Transportation Research Record, 2602, 1-19.

15. Abugaber, D. (2020). Chapter 23: using ARIMA for time series analysis. [Online] Available: https://ademos.people.uic.edu/Chapter23.html. Accessed 29 June 2020

16. Hasenjager, M., \& Wersing, H. (2018). Personalization in advanced driver assistance systems and autonomous vehicles: a review. In IEEE Conference on Intelligent Transportation Systems, Proceedings, ITSC, (pp. 1-7).

17. OICA (2016). Sales statistics 2005-2015. Paris: OICA [Online]. Available: http:// www.oica.net/category/sales-statistics/. Accessed: 29 June 2020

18. Arbib, J., \& Seba, T. (2017). Rethinking transportation 2020-2030.

19. Alonso-mora, J., Samaranayake, S., Wallar, A., Frazzoli, E., \& Rus, D. (2017). Ondemand high-capacity ride-sharing via dynamic trip-vehicle assignment. Proceedings of the National Academy of Sciences of the United States of America, 114(3), 462-467.

20. Van Meldert, B., \& De Boeck, L. (2016). Introducing autonomous vehicles in logistics: a review from a broad perspective.

21. Instituto Nacional de estadística (2020). Base de datos del Instituto Nacional de Estadística. Ourense: INE [Online]. Available: https://www.ine.es/ inebmenu/indiceAZ.htm. Accessed 29 June 2020.

22. SERNAUTO. Sector del Automóvil | SERNAUTO Proveedores de Automoción. [Online]. Available: https://www.sernauto.es/el-sector. Accessed 27 Oct 2019.

23. CNMC Comisón Nacional de los Mercados y la Competencia (2018). El comercio electrónico supera en España los 10.000 millones de euros en el tercer trimestre de 2018, casi un 30\% más que el año anterior. [Online]. Available: http://data.cnmc.es/datagraph/. Accessed: 04 Oct 2019.

24. Scherf, J. \& T. Knell (2019). What is Logistics 4.0? Everything you need to know about digitization \& logistics. MM Logistick. [Online]. Available: https://www. maschinenmarkt.international/what-is-logistics-40-everything-you-need-toknow-about-digitization-logistics-a-876611/. Accessed 28 Oct 2019.

25. Sanz, A., Vega, P., \& Mateos, M. (2014). Cuentas ecológicas del transporte, (2nd ed., ). Madrid: Ecologistas en Acción.

26. Dirección General de Tráfico (2017). Portal Estadístico - Número de pasajeros totales en España. [Online]. Available: https://sedeapl.dgt.gob.es/WEB_IEST_ CONSULTA. Accessed 28 June 2020.

27. CETRAA (Confederación Española de Talleres de Reparación de Automóviles y Afines) (2020). Nota De Prensa. [Online]. Available: https://www.cetraa.com/ acerca-de/. Accessed 29 June 2020

28. SafeWork SA (2017). Automotive workshops - work health and safety guidelines.

\section{Publisher's Note}

Springer Nature remains neutral with regard to jurisdictional claims in published maps and institutional affiliations.

\section{Submit your manuscript to a SpringerOpen ${ }^{\bullet}$ journal and benefit from:}

- Convenient online submission

- Rigorous peer review

- Open access: articles freely available online

High visibility within the field

- Retaining the copyright to your article

Submit your next manuscript at $>$ springeropen.com 